\title{
STUDIES ON EFFECT OF COAT THICKNESS ON THE MOISTURE UPTAKE BY A HARDWOOD SUBSTRATE
}

\author{
Sachin Gupta ${ }^{1}$, Asieleavio John ${ }^{1}$, V.S. Kishan Kumar ${ }^{1 *}$
}

\begin{abstract}
The moisture sorption behaviour of three coating thicknesses of shellac and polyurethane films on Dalbergia sissoo substrate is studied in this paper. The thin films of either coat failed to reduce the water vapour transmission significantly. However, the thick coats were able to reduce this rate illustrating the importance film thickness of coating used on surfaces of wood products. The increment in Moisture Content over the conditioned MC showed a clear film thickness effect in the case of PU with the increments reducing with increasing thickness. The Moisture Exclusion Effectiveness of PU coating showed better values than shellac coating with both the finishes showing a thickness effect. More importantly, the study illustrated the effect of coating thickness even when the differences are small.
\end{abstract}

Keywords: Dalbergia sissoo, coating thickness, moisture sorption, MEE, polyurethane, shellac, water vapour transmission.

\section{INTRODUCTION}

Finishing is the last but one of the most important steps in obtaining the completed wooden product. Finishing in woodworking usually describes some final surface treatment that provides protection to the wood and improves its appearance. Wood absorbs or desorbs moisture from the surroundings depending on the temperature and relative humidity of the surrounding it is exposed to. So the product needs to be protected from changes in atmospheric humidity, microorganisms, insects, dirt and surface wear, and from mechanical damage of its surface. The functional aspect of finishing therefore should take into account all these factors in the service life of a product and choose coatings appropriately.

The use of surface coatings is based on the formation of a surface film of polymeric materials, such as varnish, lacquer, or paint. As long as the coating film is perfect and has no cracks, openings, or other imperfections, water does not penetrate into the wood or depending upon the permeability of the film to liquid water or water vapour, at least any penetration is very slow. However, in practice there is no such thing as a perfect film. Microscopic cracks develop more or less rapidly depending upon the severity of exposure to weathering. Once a crack has developed, nothing can stop the penetration of 
water, which in most cases lifts the surrounding film, widens the cracks, and accelerates the destruction of the film (Borgin 1961).

The initial moisture content of wood chips naturally affects the amount of liquid penetrating into the chip voids. During penetration at $80{ }^{\circ} \mathrm{C}$ temperature and over-pressure of 9 bars, the amount of black liquor that penetrated into the heartwood chips of pine after 30 minutes was almost four times greater than the amount penetrated into sapwood chips (Malkov 2002).

During water absorption by wood materials, water molecules are held by the hydroxyl group $(\mathrm{OH})$ of cellulose and lignin until saturation (Kollmann and Cote 1984). Subsequently, the resulting moisture levels play critical roles in the success of the wood finish over the surface. The dimensional changes due to moisture present in the wood specimen could be explained in general by the moisture diffusion coefficients that are controlled in turn by capillary water uptake (Wheeler 1983, Meijer and Militz 2001).

According to Cassens and Feist (1986), finishing characteristics of coatings on wood surfaces depend on a large number of variables, of which the coating-film thickness is an important one.

Against this background, a study was conducted to understand the effect of coating thickness on the moisture uptake behaviour using Dalbergia sissoo substrate. D. sissoo is the North Indian Rosewood (a counter part of the actual rosewood, D. latifolia) locally named as shisham. The timber of this species is used for doors, windows, beams etc. (Sattar et al. 1999). Polyurethane and traditional shellac polishes were used in the study. Polyurethane varnishes are typically hard, abrasion-resistant, and durable coatings popular for hardwood floors. Its use as a moisture barrier for wood based products is already documented (Poaty et al. 2013). PU also has been reported to have good resistance against UV degradation by showing less than $15 \%$ reduction in its gloss values upon exposure to UV for more than 100 hours (Ghosh et al. 2015). Better mechanical strength, better adhesion and ease of subsequent coating are also cited as advantages of PU film (Carter 2012). Shellac is a very widely used single component resin varnish that is alcohol soluble. Due to its low cost and easiness of preparation, this finish is still favoured by many local artisans and small scale industries in India. The utility of this coating in sustained release of drugs has been studied in detail by Farag and Leopold (2011) wherein its good water resistance and film forming properties are found useful.

\section{MATERIALS AND METHODS}

70 Cubical shaped samples were prepared from plain sawn $D$. sissoo wood which had an average volume of 51,65 $\mathrm{cm}^{3}$. Out of these, 10 samples were kept as a separate set of uncoated samples. The shellac polish (SP) was prepared by dissolving shellac into denatured alcohol in a proportion of $3 \mathrm{~g}$ of shellac in $50 \mathrm{ml}$ of alcohol. The Poly Urethane (PU) used was a commercial PU clear interior wood finish from M/s Lewis Berger. This was a single pack solvent based coating. The two polishes were applied on to all the six surfaces of the samples using cloth. The 60 remaining samples were divided into 6 sets of 10 each. One set was given a single coat of PU, another set was given 2 coats of PU and a third set was given 3 coats of PU. It was ensured that successive coats were applied only after the preceding coat dried in air in dust free environment. Of the remaining 3 sets, samples in one set were given 2 coats of Shellac and those in the other two sets were given 4 and 6 coats of shellac. After giving these multiple coatings, coating thickness measurements were carried out using a DeFelsko PosiTector 200 series film thickness measuring gauge. This instrument non-destructively measures the film thickness using ultrasound technology. Three individual random readings for thickness were taken on the surfaces of each of the 60 coated samples. 
All the seventy samples were then kept for conditioning in a humidity cum temperature controlled chamber at $30 \%$ Relative Humidity $(\mathrm{RH})$ and $35^{\circ} \mathrm{C}$ temperature and the weights were monitored till they attained constant weights. The samples were placed inside the chamber on a mesh to allow the moisture to enter the samples from all the sides. Thereafter, the RH was raised to $90 \%$ without altering the temperature setting. The amounts of moisture uptake by the samples were measured as weight gain of each sample after different times of humidity exposure. The experiment was continued for 34 days until the samples attained roughly constant weights. At the end of the experiment, all the samples were oven dried at $101^{\circ} \mathrm{C}$ until they attained constant oven-dry weights (ODW).

The moisture uptake behaviour was studied by calculating the following parameters:

\section{Percent Weight Gain (PWG)}

This was calculated as

$$
P W G=\frac{\left(W_{t}-W_{0}\right)}{W_{0}} \times 100
$$

Where, $\mathrm{W}_{\mathrm{t}}$ is the weight of the sample after exposure to $90 \% \mathrm{RH}$ for time $\mathrm{t}$, and

$\mathrm{W}_{0}$ is the conditioned weight.

2. Moisture Content (MC) and increment in $\mathrm{MC}$

From the oven-dried weights (ODW), the MC of the samples were calculated as

$$
M C=\frac{(\text { Green Weight }-O D W)}{O D W} \times 100
$$

The green weights corresponded to the condition weights (corresponding to initial moisture content) and final weights at the end of high humidity exposure (corresponding to final moisture content).

The increments in $\mathrm{MC}$ were calculated as a percentage using the formula

$$
M C \text { Increment }=\frac{(F M C-I M C)}{I M C} \times 100
$$

Where FMC and IMC correspond to Final (at the end of the experiment) and Initial (Conditioned) moisture contents

3. The moisture excluding effectiveness (MEE) for the coated samples where calculated using the formula by Feist et al. (1985).

$$
M E E=\frac{(U-C)}{U} \times 100
$$


Where $\mathrm{U}$ is the weight of the moisture absorbed by the uncoated samples and $\mathrm{C}$ is the weight of the moisture observed by similar coated sample for a given period of exposure to high humidity after conditioning.

4. The water vapour transmission rate (WVTR) was calculated using the formula

$$
W V T R=\frac{W}{A x t}
$$

Where

$\mathrm{W}$ is the weight of the absorbed moisture by a conditioned sample $(\mathrm{g})$

A is the surface area (sum of areas of all six surfaces) of the sample $\left(\mathrm{m}^{2}\right)$ and

$\mathrm{t}$ is the time the conditioned sample was exposed to high humidity (days)

Statistical analyses were carried out using SPSS package.

\section{RESULTS AND DISCUSSION}

The coating thicknesses of the three sets of samples prepared are given in Table 1 .

Table 1. Film thicknesses observed with shellac and PU coatings.

\begin{tabular}{|c|c|c|c|c|c|}
\hline Coating & Coating & $\begin{array}{c}\text { Minimum } \\
(\mu \mathrm{m})\end{array}$ & $\begin{array}{c}\text { Maximum } \\
(\mu \mathrm{m})\end{array}$ & $\begin{array}{c}\text { Mean } \\
(\mu \mathrm{m})\end{array}$ & $\begin{array}{c}\text { Standard } \\
\text { Deviation }(\mu \mathrm{m})\end{array}$ \\
\hline \multirow{4}{*}{$\begin{array}{c}\text { Shellac polish } \\
(\mathrm{SP})\end{array}$} & $\begin{array}{c}\mathrm{T} 1 \\
(2 \text { coats })\end{array}$ & 46 & 55 & 49,9 & 2,5 \\
\cline { 2 - 6 } & $\begin{array}{c}\mathrm{T} 2 \\
(4 \text { coats })\end{array}$ & 50 & 59 & 54,5 & 3,0 \\
\cline { 2 - 6 } & $\begin{array}{c}\mathrm{T} 3 \\
(6 \text { coats })\end{array}$ & 49 & 68 & 56,6 & 5,7 \\
\hline \multirow{4}{*}{$\begin{array}{c}\text { Polyurethane } \\
(\mathrm{PU})\end{array}$} & $\begin{array}{c}\mathrm{T} 1 \\
(1 \text { coat })\end{array}$ & 47 & 60 & 51,4 & 3,2 \\
\cline { 2 - 6 } & $(2$ coats $)$ & 50 & 62 & 54,9 & 2,9 \\
\cline { 2 - 6 } & $\begin{array}{c}\mathrm{T} 3 \\
(3 \text { coats })\end{array}$ & 54 & 64 & 57,5 & 3,4 \\
\hline
\end{tabular}

One way ANOVA of the coating thickness values showed that the three thicknesses in each case (PU and SP) are significantly different $(\mathrm{p}<0,05)$ the ANOVA results are given in Table 2. 
Table 2. One way ANOVA of the thicknesses of the two coatings.

\begin{tabular}{|l|c|c|c|c|c|}
\hline \multicolumn{1}{|c|}{ Coating } & Sum of Squares & df & Mean Square & F & Sig. \\
\hline SP & 697,09 & 2 & 348,54 & 22,19 & 0,000 \\
\hline Error & 1367,53 & 87 & 15,72 & & \\
\hline PU & 562,20 & 2 & 281,10 & 28,51 & 0,000 \\
\hline Error & 857,40 & 87 & 9,86 & & \\
\hline
\end{tabular}

To understand the differences between each of them, Duncan's subsets were formed which are given in Table 3.

Table 3. Duncan's subsets for observed film thicknesses of shellac and PU coatings.

\begin{tabular}{|c|c|c|c|c|c|c|c|}
\hline \multirow{2}{*}{ Thick } & \multirow{2}{*}{$\mathbf{N}$} & \multicolumn{3}{|c|}{ Subsets of SP } & \multicolumn{3}{c|}{ Subsets of PU } \\
\cline { 3 - 8 } & & 1 & 2 & 3 & 1 & 2 & 3 \\
\hline T1 & 30 & 49,9 & & & 51,4 & & \\
\hline T2 & 30 & & 54,5 & & & 54,9 & \\
\hline T3 & 30 & & & 56,6 & & & 57,5 \\
\hline Sig. & & 1,0 & 1,0 & 1,0 & 1,0 & 1,0 & 1,0 \\
\hline
\end{tabular}

Table 3 clearly groups the thicknesses into three subgroups in either case thus we can safely conclude that the experimental samples investigated had significantly different coating thicknesses with both SP and PU coatings. However, a look at Table 3 reveals that the mean values of each thickness in the three groups are not very different from each other. For instance, the thicknesses of T1 are 49,9 $\mu \mathrm{m}$ for SP and $51,4 \mu \mathrm{m}$ for PU respectively. Similarly the values for T3 are $56,6 \mu \mathrm{m}$ and $57,5 \mu \mathrm{m}$ respectively. This indicates that the thicknesses under T1, T2 and T3 may not be significantly different for the two coatings studied. Hence, the individual 30 thickness readings for T1 for SP and PU were pooled which gave a mean value of $50,7 \mu \mathrm{m}(2,9 \mu \mathrm{m})$. The same was repeated with T2 and T3. Such pooled values were analysed using one way ANOVA and the results were found to be significant $(p<0,05)$. Duncan's subsets formed for these pooled thicknesses are given in Table 4.

Table 4. Duncan's subsets for pooled thicknesses of the two coatings.

\begin{tabular}{|c|c|c|c|c|}
\hline \multirow{2}{*}{ Pooled thickness } & \multirow{2}{*}{$\mathbf{N}$} & \multicolumn{3}{|c|}{ Subset for pooled values of SP and PU thicknesses $(\mu \mathrm{m})$} \\
\cline { 3 - 5 } & & $\mathbf{1}$ & $\mathbf{2}$ & $\mathbf{3}$ \\
\hline $\mathrm{T} 1$ & 60 & $50,7(2,9)$ & & \\
\hline $\mathrm{T} 2$ & 60 & & $54,7(2,9)$ & $57,0(4,7)$ \\
\hline T3 & 60 & & & 1,0 \\
\hline Sig. & & 1,0 & 1,0 & \\
\hline
\end{tabular}

Note: values in parentheses give the standard deviations

Table 4 clearly illustrates that the thicknesses can be easily divided into three groups with mean values of $50,7 \mu \mathrm{m} ; 54,7 \mu \mathrm{m}$ and $57 \mu \mathrm{m}$ respectively irrespective of the coating material used.

Accordingly the three thicknesses were renamed as T50, T54 and T57 respectively for T1, T2 and T3. This facilitated in using similar thicknesses of the two coating materials (SP and PU) for comparing their performance in moisture uptake. It is pertinent to mention that Rajput et al. (2014) have reported 60-70 $\mu \mathrm{m}$ thicknesses for bio-based PU coatings. The average thickness obtained on chestnut and pine surfaces for two coats of an acrylic varnish containing polyurethane were about $55 \mu \mathrm{m}$ and $66,5 \mu \mathrm{m}$ which was attributed to the greater volume of voids in pine (Fernandez et al. 2013). 


\section{The conditioned moisture contents of the samples}

The moisture sorption was conducted after conditioning all the samples at $35^{\circ} \mathrm{C}$ and $30 \%$ humidity. From the Oven dry weights determined after the completion of the experiment, the actual moisture contents (MC) attained by each sample including the set of uncoated samples were calculated. The values are given in following Table 5.

Table 5. Initial MC (\%) of the samples.

\begin{tabular}{|c|c|c|c|c|c|}
\hline Coating & Coating thickness & Minimum & Maximum & Mean & $\begin{array}{c}\text { Standard } \\
\text { Deviation }\end{array}$ \\
\hline Uncoated & & 6,07 & 6,38 & 6,24 & 0,10 \\
\hline \multirow{2}{*}{$\begin{array}{c}\text { Shellac polish } \\
\text { (SP) }\end{array}$} & T50 & 6,15 & 6,40 & 6,25 & 0,10 \\
\cline { 2 - 6 } & $\mathrm{T} 54$ & 6,24 & 6,54 & 6,41 & 0,09 \\
\cline { 2 - 6 } & $\mathrm{T} 57$ & 6,03 & 7,09 & 6,35 & 0,30 \\
\hline \multirow{2}{*}{$\begin{array}{c}\text { Polyurethane } \\
\text { (PU) }\end{array}$} & $\mathrm{T} 50$ & 6,00 & 6,38 & 6,24 & 0,11 \\
\cline { 2 - 6 } & $\mathrm{T} 54$ & 6,06 & 6,57 & 6,39 & 0,17 \\
\cline { 2 - 6 } & $\mathrm{T} 57$ & 5,94 & 6,63 & 6,36 & 0,23 \\
\hline
\end{tabular}

The one way ANOVA of these MCs in conditioned state revealed that they do not differ significantly for the coated and uncoated samples with either of the coating used $(p>0,05)$. Thus we can safely assume that all the samples have reached their EMCs under the conditioning environment. Analysis of the pooled IMC data ( 70 samples) also yielded a p-value of 0,136 showing that these do not vary significantly. The average value for all the 70 samples worked out to be $6,32 \%$ (ranging from $5,94 \%$ to $7,09 \%$ ) with a standard deviation of only $0,18 \%$. This value is quite close to the reported EMC value of 5,5\% for D. sissoo at $30 \% \mathrm{RH}$ and $35^{\circ} \mathrm{C}$ in an earlier work (Rehman and Singh 1969).

\section{Final Moisture contents of the samples}

It would now be interesting to look at the actual final MCs attained by these samples after 34 days of exposure to high humidity $(90 \%)$ at the same temperature of $35^{\circ} \mathrm{C}$. Table 6 gives the means of the final moisture content (FMC) values calculated from the measured OD weights of each samples.

Table 6. Final MC (\%) of the samples.

\begin{tabular}{|l|c|c|c|c|c|c|}
\hline Coating & $\begin{array}{c}\text { Coating } \\
\text { thickness } \\
(\mu \mathrm{m})\end{array}$ & Minimum & Maximum & Mean & $\begin{array}{c}\text { \% reduction } \\
\text { Standard } \\
\text { Deviation } \\
\text { in FMC with } \\
\text { respect to } \\
\text { the uncoated } \\
\text { samples }\end{array}$ \\
\hline Uncoated & & 15,27 & 16,00 & 15,60 & 0,24 & - \\
\hline \multirow{2}{*}{$\begin{array}{l}\text { Shellac polish } \\
(\mathrm{SP})\end{array}$} & 50 & 14,50 & 15,80 & 15,17 & 0,34 & 2,76 \\
\cline { 2 - 7 } & 54 & 14,97 & 15,83 & 15,36 & 0,28 & 1,54 \\
\hline \multirow{2}{*}{$\begin{array}{l}\text { Polyure- } \\
\text { thane (PU) }\end{array}$} & 57 & 14,46 & 16,13 & 14,98 & 0,47 & 3,97 \\
\cline { 2 - 7 } & 54 & 14,19 & 17,26 & 14,79 & 0,93 & 5,19 \\
\hline
\end{tabular}

It can be seen from Table 6 that generally the coated samples have attained lesser FMCs compared to the uncoated ones. The thickest coating in either polish has resulted in lesser FMC demonstrating 
a thickness effect in moisture sorption. An analysis of the FMCs of the samples clearly grouped the uncoated samples in the highest groups. However, the FMCs attained by the coated samples were not significantly different in general. The EMC of this species reported in an early work at $35^{\circ} \mathrm{C}$ and $95 \%$ $\mathrm{RH}$ is $17,6 \%$ which is close to the present value of $15,27 \%$ to $16 \%$ attained by the uncoated samples in the present work (Rehman and Singh 1969).

However, the FMCs attained by the coated samples are not hugely lower corresponding to the uncoated samples. This indicates that the filling up of the lumens is yet to begin even after 34 days of exposure at $90 \%$ RH. Thygesen et al. (2010) had concluded from their studies on modified and unmodified Norway Spruce that sorption of capillary water is insignificant below $99,5 \% \mathrm{RH}$. Any significant capillary sorption below fibre saturation has also been ruled out throughout the hygroscopic range in native wood (Engelund et al. 2013). The reported fibre saturation point for D. sisoo is 20,9\% (Pandey and Jain 1992).

Table 6 also gives the $\%$ reduction in final moisture content shown by coated samples with respect to the uncoated samples. It can be observed that the SP samples shows a reduction of less than $4 \%$ in FMC and thinner coats actually do not show a clear pattern. However, in the case of PU, the reductions are always greater than $5 \%$ and also show a clear pattern with increasing thickness resulting in increasing reduction in FMC. The thickest PU coat has resulted in a 7\% reduction in FMC compare to uncoated samples.

To understand this moisture uptake better, percentage increase in the final MC over the conditioned EMC of each sample was calculated. For uncoated samples, this ranged between 144,7 \% and 161,3 $\%$. The thinnest coats of Shellac and PU showed a MC increase of $132,8 \%$ to $151,8 \%$ and $125,7 \%$ to $174,1 \%$ respectively. For the thickest coats the respective MC increments were $126,7 \%$ to $140,9 \%$ and $118,1 \%$ to $136,5 \%$. The mean MC increment values are given in Figure 1.

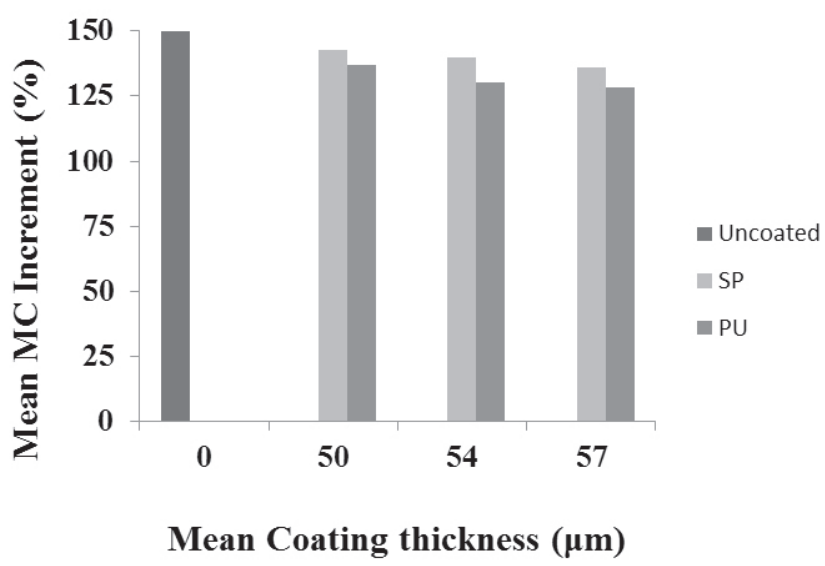

Figure 1. Mean MC increments over IMCs.

The Figure indicates that the mean increments in MC lie between $125 \%$ and $150 \%$ over the initial (conditioned) MCs. The data on MC increments of all the 70 samples was analysed using oneway ANOVA to look for any differences between these values. Both the coatings showed significant differences in the increments registered in $\mathrm{MC}$ when compared along with the uncoated samples. The results of ANOVA are given in Table 7. 
Table 7. ANOVA of MC increments over condition IMCs.

\begin{tabular}{|l|c|c|c|c|c|}
\hline \multicolumn{1}{|c|}{ Source of variation } & Sum of Squares & df & Mean Square & F & Sig. \\
\hline Coating thickness & 8133,05 & 6 & 1355,51 & 46,42 & 0,000 \\
\hline Error & 1839,79 & 63 & 29,20 & & \\
\hline
\end{tabular}

To understand difference between the coating thicknesses and the two finishes used, Duncan's subsets were formed which are given in Table 8.

Table 8. Duncan's subsets for MC increments over conditioned IMCs.

\begin{tabular}{|l|c|c|c|c|c|c|c|}
\hline \multirow{2}{*}{ Coat thickness } & \multirow{2}{*}{$\mathbf{N}$} & \multicolumn{7}{|c|}{ Subsets of MC increments (\%) } \\
\cline { 3 - 8 } & & 1 & 2 & 3 & 4 & 5 & 6 \\
\hline PUT57 (T1) & 10 & 116,9 & & & & & \\
\hline PUT54 (T2) & 10 & & 122,2 & & & & \\
\hline PUT50 (T3) & 10 & & & 130,7 & & & \\
\hline SPT57 (T1) & 10 & & & & 135,9 & & \\
\hline SPT54 (T2) & 10 & & & & 139,8 & 139,8 & \\
\hline SPT50 (T3) & 10 & & & & & 142,7 & \\
\hline Uncoated & 10 & & & & & & 150,1 \\
\hline Sig. & & 1,000 & 1,000 & 1,000 & 0,107 & 0,237 & 1,000 \\
\hline
\end{tabular}

It can be seen from the Duncan's table (Table 8) that the PU coating shows significantly lower MC increments and clearly shows a thickness effect. The SP coats though show lesser MC increments than the uncoated samples, the grouping is not as evident as seen in PU since T2 finds itself grouped both with the thinnest (T1) and the thickest (T3) coating. This trend of SP not showing clear thickness effect with thinner coats is consistent with results obtained in Table 6 also. In general the increment values are less for PU coated samples.

The percentage weight gains (PWG) exhibited by the samples due to exposure to $90 \% \mathrm{RH}$ after different exposure times are given in Table 9. For comparison the gains exhibited by the uncoated samples are also shown in the same table.

Table 9. PWG of coated and uncoated samples.

\begin{tabular}{|l|l|l|c|c|c|c|c|}
\hline \multirow{2}{*}{$\begin{array}{c}\text { Time of } \\
\text { exposure } \\
(\mathrm{h})\end{array}$} & \multirow{2}{*}{ Uncoated } & \multicolumn{3}{|c|}{ Shellac coating (\%) } & \multicolumn{3}{c|}{ PU coating (\%) } \\
\cline { 3 - 8 } & & T50 & T54 & T57 & T50 & T54 & T57 \\
\hline 72 & 7,73 & 7,10 & 6,76 & 6,30 & 6,16 & 5,68 & 4,47 \\
\hline 168 & 8,19 & 7,58 & 7,28 & 6,86 & 7,01 & 6,97 & 6,51 \\
\hline 312 & 8,39 & 7,96 & 7,62 & 7,41 & 7,60 & 7,37 & 7,22 \\
\hline 480 & 8,59 & 8,16 & 8,01 & 7,81 & 7,79 & 7,62 & 7,43 \\
\hline 816 & 8,81 & 8,39 & 8,42 & 8,11 & 8,04 & 7,82 & 7,66 \\
\hline
\end{tabular}

Table 9 reveals that the uncoated samples gained $8,81 \%$ weight over their original conditioned weights in 816 hours. All the coated samples exhibited lesser weight gains. For example the thickest coating of PU resulted in 7,66 \% weight gain whereas that of shellac showed $8,11 \%$ weight gain. The gains with thinnest coats were $8,39 \%$ and $8,04 \%$ respectively for shellac and PU. The efficiency of PU seems to be much better in controlling moisture entry into the substrate. The efficiency of any coating in controlling moisture entry into a wood substrate depends on the type of wood also. The wood of $D$. sissoo belongs to the diffuse porous category (Quirk 1983, Lei et al. 2011). The water uptake of such hardwoods is reported to be higher (Michalec and Niklasova 2006). Thus the wood coatings are not 
expected to reduce the moisture intake into this wood substrate substantially especially on prolonged exposure to high RH. However, it can be noticed that in the initial stages, the moisture blocking is quite effective with thick coatings. The thickest PU coated samples showed only $4,47 \%$ weight gain against $7,73 \%$ by uncoated samples after $72 \mathrm{~h}$ of exposure. The day wise PWG of the samples are shown in Figures 2 and 3.

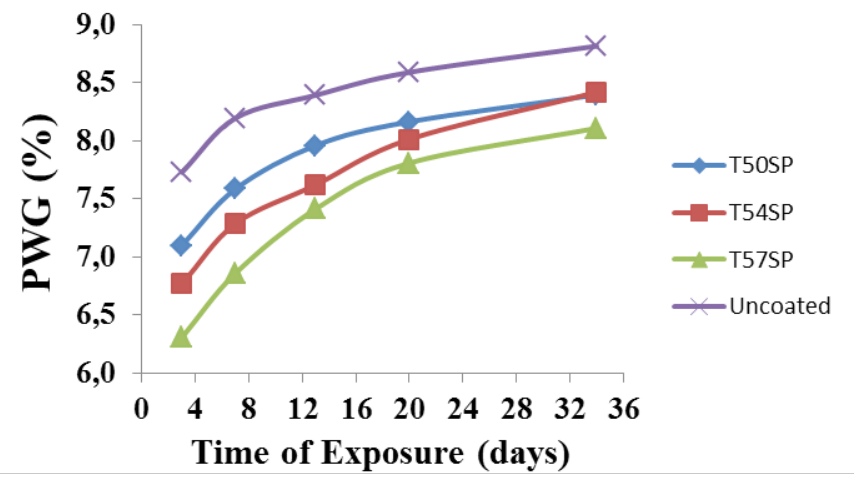

Figure 2. PWG of Shellac coated samples.

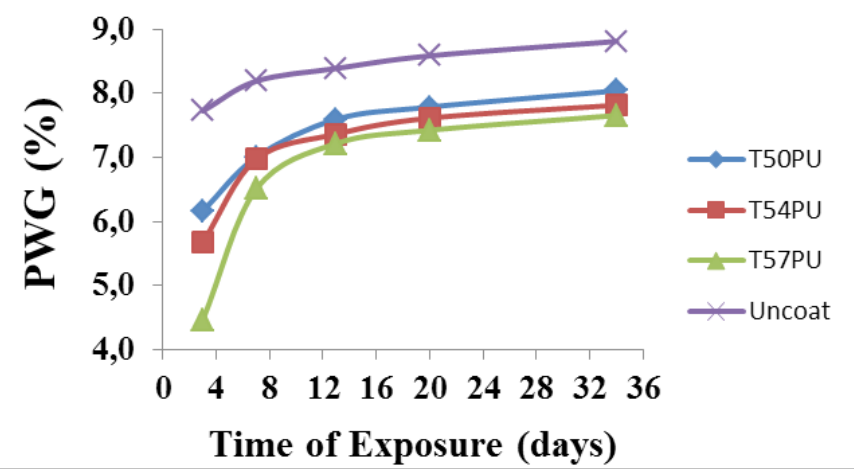

Figure 3. PWG of PU coated samples.

Figures 2 and 3 give a clearer picture of the pattern of moisture uptake by the two types of coatings. Figure 1 suggests that even after 34 days of exposure, the shellac coating may still be allowing some moisture to be taken in at some rate. On the other hand, the PU samples seem to be allowing most of the uptake early in the initial stages. From around the $8^{\text {th }}$ day onwards, the uptake seems to be rather too slow (Figure 3). The slopes of the sorption curves in the initial stages are steeper for PU coated samples. The most probable reason could be the longer resistance of PU coats under high humidity at the given temperature. Schniewind and Arganbright (1984) argue that Urethane can be a very effective moisture barrier, particularly because it can be applied in film thicknesses which are 5 to 10 times greater than those of some other coatings. Considerable lowering of percent weight gains by increasing the number (film thickness) of epoxy coatings on Douglas fir plywood blanks exposed to high RH has been reported by Niederer (2007).

Using the weight gains of the coated and uncoated samples, the Moisture Exclusion Effectiveness (MEE) for the samples coated with the three thicknesses were calculated. These values are given in Table 10 for the two coating materials for different exposure times. 
Table 10. MEE SP and PU coated samples with the three coating thicknesses.

\begin{tabular}{|c|c|c|c|c|c|c|}
\hline \multirow{2}{*}{$\begin{array}{c}\text { Exposure Time } \\
(\mathrm{h})\end{array}$} & \multicolumn{2}{|c|}{$\mathbf{5 0}(\mu \mathrm{m})$} & \multicolumn{2}{c|}{$\mathbf{5 4}(\mu \mathrm{m})$} & \multicolumn{2}{c|}{$\mathbf{5 7}(\mu \mathrm{m})$} \\
\cline { 2 - 7 } & $\mathbf{P U}$ & $\mathbf{S P}$ & $\mathbf{P U}$ & $\mathbf{S P}$ & $\mathbf{P U}$ & $\mathbf{S P}$ \\
\hline 72 & 15,31 & 5,96 & 23,58 & 11,30 & 40,53 & 19,01 \\
\hline 168 & 9,23 & 5,26 & 11,48 & 9,95 & 18,33 & 16,93 \\
\hline 312 & 3,91 & 2,93 & 8,72 & 8,04 & 11,53 & 12,34 \\
\hline 480 & 3,79 & 2,74 & 7,81 & 5,54 & 11,07 & 9,79 \\
\hline 816 & 3,18 & 2,52 & 7,79 & 3,30 & 10,64 & 8,70 \\
\hline
\end{tabular}

From Table 10, it can be seen that in general, the PU coat exhibits higher MEEs consistently. The difference between PU and Shellac coats is very marked especially in the initial exposure duration where PU coats result in more than double MEE compared to shellac. The low MEE for shellac polish even in initial stages of humidity exposure on mango wood substrate is already reported (Kishan Kumar et al. 2009). When mango samples with initial moisture content of about $10,1 \%$ were exposed to 87 $\% \mathrm{RH}$ at $50^{\circ} \mathrm{C}$, the MEE observed after $72 \mathrm{hrs}$ was $17,6 \%$. However, the difference in MEEs of PU and Shellac in the present experiment slows down as the exposure time increases. What is important to notice is that even a $57 \mu \mathrm{m}$ thick coating seems to be insufficient in either case if the coated specimen is to spend longer times in humid environment. After 34 days, $(816 \mathrm{hrs}$.) the MEE of PU and Shellac are just $10,64 \%$ and $8,7 \%$ only. Thus one has to adopt much thicker coatings for use in humid conditions when using these surface coatings. It also indicates that with sufficient thickness, the shellac coat can be nearly equally effective as PU in controlling moisture transport. The MEE values obtained in this study are much lower than those obtained for shellac and PU applied in three coats on Ponderosa pine sapwood which were conditioned at $27^{\circ} \mathrm{C}$ and $30 \% \mathrm{RH}$ and were then exposed to $90 \% \mathrm{RH}$ at the same temperature for 14 days (Cassens and Feist 1986). This can be attributed to the more porous nature of D. sissoo. The values reported for three PU gloss varnishes by Feist et al. (1985) for three coats of the finish varied from $31 \%$ to $44 \%$ after 14 days of exposure to $90 \%$ humidity but again when the wood substrate was Ponderosa pine.

The moisture uptake in uncoated samples is a function of the properties of the wood substrate used viz: the permeability of wood to water vapours, the diffusivity etc. However, in the case of coated samples, the coats restrict the entry of rate of vapour absorption. This is usually expressed in terms of the water vapour penetration rates (WVTR) calculated as the weight of moisture absorbed per unit surface area per unit time (expressed in $\mathrm{g} / \mathrm{m}^{2} /$ day).

These values were calculated for each set of the samples and it was found that the WVTR ranged between $10,51 \mathrm{~g} / \mathrm{m}^{2} /$ day and $11,47 \mathrm{~g} / \mathrm{m}^{2} /$ day for the coated samples depending on the coating used and the thickness of the coat. For the uncoated samples, the WVTR was $11,77 \mathrm{~g} / \mathrm{m}^{2} /$ day. The analysis of WVTR data showed that both the coatings showed a thickness effect and the rates decreased with increasing coat thicknesses. To compare the efficacy of SP and PU, all the WVTR data were analysed together and it was found that there was significant differences between the WVTR values. The Duncan subsets formed are given in Table 11. 
Table 11. Duncan subsets for WVTRs of the samples.

\begin{tabular}{|c|c|c|c|}
\hline \multirow{2}{*}{$\begin{array}{c}\text { Thickness of coats } \\
(\mu \mathrm{m})\end{array}$} & \multirow{2}{*}{ Number of samples } & \multicolumn{2}{|c|}{ WVTR $\left(\mathrm{g} / \mathrm{m}^{2} /\right.$ day $)$ Subsets } \\
\cline { 3 - 4 } & & 1 & 2 \\
\hline $57(\mathrm{PU})$ & 10 & 10,52 & \\
\hline $57(\mathrm{SP})$ & 10 & 10,75 & \\
\hline $54(\mathrm{PU})$ & 10 & 10,85 & \\
\hline $54(\mathrm{SP})$ & 10 & & 11,38 \\
\hline $50(\mathrm{PU})$ & 10 & & 11,40 \\
\hline $50(\mathrm{SP})$ & 10 & & 11,47 \\
\hline Uncoated & 10 & 0,208 & 11,77 \\
\hline Sig. & & & 0,156 \\
\hline
\end{tabular}

It is interesting to notice that $50 \mu \mathrm{m}$ thickness in the case of PU and $50 \mu \mathrm{m}$ and $54 \mu \mathrm{m}$ in the case of SP are grouped along with WVTR values of uncoated samples. Thus we can conclude that for efficient reduction in vapour transmission rates, one has to give a coating thickness exceeding $54 \mu \mathrm{m}$ in the case of SP. However, transmission rate of PU with both $54 \mu \mathrm{m}$ and $57 \mu \mathrm{m}$ thicknesses do not seem to differ significantly. It is pertinent to mention that there are reports of water vapour transmission rates in the range of 38 to $330 \mathrm{~g} / \mathrm{m}^{2} /$ day at a high temperature of $70^{\circ} \mathrm{C}$ and $91 \% \mathrm{RH}$ for PU foams of varying densities (Boyd and Daalen 1976). However, these rates could be reduced considerably (by 37 to $95 \%$ ) by applying Butyl and epoxy coatings of about $500 \mu \mathrm{m}$ thickness. Even materials like beeswax and paraffin have been reported to reduce the WVTR of microfibrillated cellulose films considerably (Spence et al. 2011). The effects of sample thickness on the barrier property of water vapour were studied for three different unmodified paper samples and it was shown that the WVTR indeed decreased with the thickness (Bedane et al. 2012).

It is to be noted that though PU shows in general lower WVTRs, the absolute values of WVTR of PU and shellac coated samples are not vastly different. For instance the thickest PU and shellac coated samples resulted in $10,52 \mathrm{~g} / \mathrm{m}^{2} /$ day and $10,75 \mathrm{~g} / \mathrm{m}^{2} /$ day of WVTR. The fact that shellac films provide low permeability for water vapour and gases is already reported (Hagenmaier and Shaw 1991). This low permeability for water vapour and gases qualifies shellac as a moisture protective coating for water sensitive formulations (The et al. 2008). The question would be the thickness of the film that has to be built up. Urethane (used in PU finishes) can perform as a very effective moisture barrier in spite of its not too low permeability. This is mainly due to the fact that it can be applied in considerable thicknesses by applying multiple coats. Use of spray applied polyurethane foams as insulation to roofing and walls to avoid humidity build up inside rooms also have been suggested where greater thickness for the insulating material is suggested to lower the water vapour transmission (PFCD 1991).

\section{CONCLUSIONS}

Samples of D. sissoo could be coated with shellac and polyurethane in uniform film thicknesses. The coated samples conditioned at $35^{\circ} \mathrm{C}$ and $30 \% \mathrm{RH}$ attained lower final moisture contents when exposed to $90 \% \mathrm{RH}$ after 34 days. The increment in MC over the conditioned MC showed a clear film thickness effect in the case of PU even with such small differences in the film thicknesses. The PU coated samples showed most of the moisture sorption in the first 8 days after which the rates became much slower. The water vapour transmission rates of thinnest coatings $(50 \mu \mathrm{m})$ of either finish were similar to that of uncoated samples. The PU coating resulted in better Moisture Exclusion Effectiveness than shellac coating. 


\section{ACKNOWLEDGEMENTS}

The authors are thankful to Director, FRI, Dehradun for the encouragement and ICFRE, Dehradun for funding this study. The encouragement by Head of Forest Products Division and the help rendered by the staff of Wood Working and Finishing Discipline are acknowledged. Special thanks are due to Head, Genetics and Tree Propagation Division for extending the humidity chamber facility.

\section{REFERENCES}

Bedane, A.H.; Huang, Q.; Xiao, H.; Eić, M. 2012. Mass transfer of water vapor, carbon dioxide and oxygen on modified cellulose fiber-based materials. Nordic Pulp and Paper Research Journal 27(2):409-417.

Borgin, K. 1961. The effect of water repellents on the dimensional stability of wood. Norsk Skogindustri 11:507-521.

Boyd, J.M.; Daalen, D.V. 1976. Water vapour barrier coatings for Poly Urethane foams. Report No. HDL-76-14, US Army Materiel Development \& Readiness Command, Alexandria, VA 22333, $16 \mathrm{p}$. 21.

Carter, N. 2012. Scavenge moisture and cut pinholes in a trice. European Coatings Journal 6:18-

Cassens, D. L.; Feist, W.C. 1986. Finishing Wood Exteriors: Selection, Application, and Maintenance. Research Paper of U.S. Department of Agriculture, Forest Service, Agriculture Handbook No. 647, Forest Products Laboratory Madison, WI. 60 p

Engelund, E.T.; Thygesen, L.G.; Svensson, S.; Hill, C.A.S. 2013. A critical discussion of the physics of wood-water interactions. Wood Sci Technol 47:141-161.

Farag, Y.; Leopold, C.S. 2011. Investigation of drug release from pellets coated with different shellac types. Drug Development and Industrial Pharmacy 37(2):193-200.

Feist, W.C.; Little, J.K.; Wennesheimer, J.M. 1985. The Moisture Excluding Effectiveness of Finishes on Wood Surfaces. Res. Pap. FPL 462 Madison, WI: U.S. Department of Agriculture, Forest Service, Forest Products Laboratory; 38p.

Fernández, I.; Fernández, M. Á.; Rodríguez, K.; Baño, V.; Dieste, A. 2013. The effect of wood species on the anti-skid resistance of coatings. Maderas-Cienc Tecnol 15(1):65-72.

Ghosh, M.; Gupta, S.; Kishan Kumar, V.S. 2015. Studies on the loss of gloss of shellacand Polyu rethane finishes exposed to UV. Maderas-Cienc Tecnol 17(1):39-44.

Hagenmaier, R.D.; Shaw, P.E. 1991. Permeability of Shellac Coatings to Gases and Water Vapor. J Agric Food Chem 39:825-829.

Kishan Kumar, V.S.; Upadhyay, K.K.; Gupta, S. 2009. Studies on moisture resistance of a traditional and a commercial finish on mango wood at elevated temperature and high relative humidity. J Indian Academy of Wood Sciences 6 (1\&2):36-44. 
Kollmann, F.P.; Cote, W.F. 1984. Solid wood, Principles of wood science and technology. Reprint Springer-Verlag, Tokyo, Vol.1: 180p.

Lei, S.; Qingfeng, S.; Jiang, D. 2011. Primary study on the anatomical construction and physicalmechanical-properties of introduced Dalbergia sisoo. Advanced MaterialsResearch 179-180:14461452.

Malkov, S. 2002. Studies on liquid penetration into softwood chips - experiments, models and applications. Helsinki University of Technology, Laboratory of Pulping Technology Reports, Series A29, Department of Forest Products Technology, p 24-26.

Meijer, M. D.; Militz, H. 2001. Moisture transport in coated wood. Part 2: Influence of coating type, film thickness, wood species, temperature and moisture gradient on kinetics of sorption and dimensional change. European Journal of Wood and Wood Products 58 (6):467-475.

Michalec, J.; Niklasova, S. 2006. Water uptake of hardwoods. Thesis work no. TD083/2006, Dept. of forest and wood technology, Vaxjo University, School of Technology and design, TD. 10p.

Niederer, B. 2007. Moisture Exclusion Effectiveness - Accelerated testing in our environmental huts. Epoxy works, No. 25:1-2.

Pandey C.N.; Jain, V.K. 1992. Wood seasoning Technology. Publication No. ICFRE 20, Indian Council of Forestry Research and Education, Dehradun, INDIA, pp 144.

PFCD-MVT-3/91.1991. Moisture vapour transmission. Polyurethane Foam Contractors Division, The Society of the Plastic Industry, Inc. Washington DC, pp 11.

Poaty, B.; Riedl, B.; Blanchet, P.; Blanchard, V.; Stafford, L. 2013. Improved water repellency of black spruce wood surfaces after treatment in carbon tetrafluoride plasmas. Wood Sci Technol 47:411-422.

Quirk, J.T. 1983. Data for a computer-assisted wood identification system I. Commercial legumes of tropical Asia and Australia. IAWA Bulletin 4(2-3):118-130.

Rajput, S.D.; Mahulikar, P.P.; Gite, V.V. 2014. Biobased dimer fatty acid containing two pack polyurethane for wood finished coatings. Progress in OrganicCoatings 77:38-46.

Rehman, M.A.; Singh, G. 1969. Wood water relationship: Equilibrium moisture content of Indian woods. J Timber Development Association of India 15(1):30-34.

Sattar, M.A.; Bhattacharjee, D.K.; Kabir, M.F. 1999. Physical and mechanical Properties and uses of timbers of Bangladesh. Bangladesh Forest Research Institute, Chittagong, pp 57.

Schniewind, A.P.; Arganbright, D.G. 1984. Coatings and Their Effect on Dimensional Stability of Wood. Waac Newsletter 6(2):2-5.

Spence, K.L.; Venditti, R.A.; Rojas, O.J.; Pawlak, J.J.; Hubbe, M.A. 2011. Water vapour barrier properties of coated and filled microfibrillated cellulose composite films. BioResources 6(4):43704388.

The, D.P.; Debeaufort, F.; Luu, D.; Voilley, A. 2008. Moisture Barrier, Wetting and Mechanical Properties of Shellac/Agar or Shellac/Cassava Starch Bilayer Bio-Membrane for Food Applications. $J$ Memb Sci 325:277-283. 
Thygesen, L.G.; Engelund, E.T.; Hoffmeyer, P. 2010. Water sorption in wood and modified wood at high values of relative humidity-Part 1: results for untreated, acetylated, and furfurylated Norway spruce. Holzforschung 64:315-323.

Wheeler, E.A. 1983. Wood structure and properties: Finishing eastern hardwoods. Forest Research Society Products, Madison, 5-14. 